\title{
Albumin-V: Role in Bovine Spermatozoa Viability, Motility and Membrane Elasticity
}

\author{
Siti Fatimah Ibrahim ${ }^{1}$, Athifah Ariff Johor ${ }^{1}$, Farahwahida Othman ${ }^{1}$, Lee Pei Yee ${ }^{1}$, Mohamad Firdaus Yahaya ${ }^{1}$, \\ Farah Hanan Fatihah Jaafar ${ }^{1}$, Noraina Mohd Bakri ${ }^{1} \&$ Khairul Osman ${ }^{2}$ \\ ${ }^{1}$ Department of Physiology, UKM Medical Center, Jalan Raja Muda Abdul Aziz, Kuala Lumpur, Malaysia \\ ${ }^{2}$ Centre of Diagnostic Science and Applied Health, Faculty of Health Sciences, National University of Malaysia, \\ Kuala Lumpur, Malaysia \\ Correspondence: Siti Fatimah Ibrahim, Department of Physiology, UKM Medical Center, Jalan Raja Muda \\ Abdul Aziz 50300, Kuala Lumpur, Malaysia. Tel: 60-3-9289-7641. E-mail: siti_fatimah31@yahoo.com
}

Received: November 21, 2012 Accepted: January 16, 2013 Online Published: February 5, 2013

doi:10.5539/jas.v5n3p83 URL: http://dx.doi.org/10.5539/jas.v5n3p83

\begin{abstract}
Semen preservation is an important process to ensure semen quality is sufficient for assisted reproductive technology. Studies have showed that suppression of free radicals, crystal formation and regulation of extracellular osmotic pressure is essential to ensure survivability. Past studies have indicated that utilizing protein already existent in the body could be used as a free radical scavenger and osmotic regulator - a potential preservation agent. Thus, the objective of this study was to determine the effect of different albumin- $V$ concentrations on pooled bovine spermatozoa. Pooled cryopreserved semen straws were thawed and incubated in different concentrations of albumin-V $\left(0,0.2,0.4,0.6,0.8,1.0 \mathrm{mg}\right.$ albumin-V/ml Bio-excel ${ }^{\circledR}$ extender $)$ at $4^{\circ} \mathrm{C}$. Sperm motility and viability were analyzed at 0, 2, 24 and 48 hours using Makler Chamber. Results indicated that motility and viability were noticeably reduced against time except for sperm incubated in $0.4 \mathrm{mg} / \mathrm{ml}$. Membrane elasticity study using atomic force microscope (AFM) was then conducted on $0,0.4$, and $1.0 \mathrm{mg} / \mathrm{ml} 48$ hours spermatozoa. We had observed that sperm membrane in the $0.4 \mathrm{mg} / \mathrm{ml}$ had a lower elasticity value $(1.7 \pm 0.6 \mathrm{kPA})$ compared to fresh semen $(5.5 \pm$ $1.0 \mathrm{kPA}), 0 \mathrm{mg} / \mathrm{ml}(5.5 \pm 0.1 \mathrm{kPA})$ and $1.0 \mathrm{mg} / \mathrm{ml}(5.3 \pm 0.9 \mathrm{mg} / \mathrm{ml})$. It is very likely that the motility and viability reduction was partly due to the changes in spermatozoa membrane elasticity. We conclude that albumin- $\mathrm{V}$ is a potential molecule for $4^{\circ} \mathrm{C}$ semen preservation; varying albumin concentration will have an influence on the spermatozoa membrane and affect the overall outcome of semen quality. Further study is required to elucidate the function and mechanism of albumin- $\mathrm{V}$ in preservation and its direct effect on ART outcome.
\end{abstract}

Keywords: albumin- $\mathrm{V}$, spermatozoa, membrane elasticity, semen preservation

\section{Introduction}

Mass artificial insemination (AI) on female cattle in heat is a common procedure in any large dairy or feedlotting farms. Its main objective is to quickly increase animal population at a relatively low cost compared to conventional method of animal importation. Despite the low cost, it is essential that to obtain a high successful rate, an experienced operator, proper synchronization of female cattle heat, good quality semen and fresh thawed semen from cryopreservation is essential (Farstad \& Berg, 1989). Since semen cryopreservation requires large amount of liquid nitrogen, conducting $\mathrm{AI}$ in a remote village is difficult and sometimes logistically impossible. To solve this problem, an alternative method for preservation is urgently needed while maintain semen quality.

The earliest effort to culture mammalian cell was in 1940s where culture media contain solely of human plasma or serum. Only then, in 1990s the well defined albumin media additive was introduced. Today, albumin is universally added in culture media for in vitro fertilization (IVF) and as a cryoprotectant for semen cryopreservation as it is well-known to be beneficial (Blake et al., 2002; Cabrita et al., 2001). Albumin makes up sixty percent of the total protein in the plasma. It has a large surface area and abundant binding sites. Albumin is able to bind to a number of substances such as fatty acid, fat soluble vitamins (A, D, E, and K), cations (calcium, magnesium, zinc), and some toxins (bilirubin, uremic toxin, certain drug) (Ghuman et al., 2005). The binding of albumin to hydroperoxy fatty acid that can be damaging to the sperm membranes make albumin as a potent lipid peroxidation inhibitor (Alvarez \& Storey, 1995). Despite of all the advantages, if the media is too concentrated with albumin, it will pull the water out from the cell (osmotic effect) which may lead to shrinkage and crystallization of the cell. 
Sperm quality can be determined by the sperm motility and DNA content. Study has showed that sperm with low motility is a good predictor for low fertilization rate in assisted conception (Freeman et al., 2001). Sperm DNA with good integrity will have significantly better result in artificial reproduction technique (ART) (Bungum et al., 2007). As sperm motility is defined as the ability of sperm to move towards an egg, it is logical that andrologist categorized semen quality into four grades. These are A grade; rapid progressive motility, B; slow or sluggish progressive motility, C; non-progressive motility, and D; immotile. According to World Health Organization (WHO) 1992, sperm motility is define as $50 \%$ or more with forward progression (categories A and B) or $25 \%$ or more with rapid progression (category A) within 60 minutes of ejaculation. Earlier studies have proven that sperm structure, DNA integrity and its environmental factors would determine percentage of viability, motility and morphology in the semen. It has also shown that increased DNA damage is associated with defect in sperm morphology and reduction in motility and viability percentage (Ruiz-Lopez et al., 2010). The aberrant form such as sperm with large, small, tapered or crooked heads or kinky, curled or double tails are less likely to fertilize an egg.

Elasticity is defined as an ability of sperm to recover its shape once deforming force are removed. This trait is important since it helps the sperm to move through the cervix until it meets the ovum in the fallopian tube. Membrane elasticity has been known to be compromised in the presence of malnutrition and excessive lipid peroxidation. In malnutrition, the sperm membrane is not well developed due to protein, carbohydrate, and lipid depletion. Lipid peroxidation process on the other hand may be triggered by free radical production through pollution, radiation and stress (Kothari et al., 2010). This process may be damaging to the sperm membrane thus altering its elasticity. Since direct assessment of cell elasticity would require direct contact of a probe with the cell membrane, an Atomic Force Microscopy (AFM) was used to elucidate the cell's elastic properties.

AFM had been invented in 1986 by Binnig, Quate and Gerber. It has now been used extensively to determine the three-dimensional image of sperm including the information about the defects in its membrane integrity (Girasole et al., 2010). By providing images at nano-resolution, AFM is assisting researcher to get a better understanding of spermatozoa factor that contribute to a successful artificial insemination procedure. Thus improving ART successful rate (Orsini et al., 2010).

Due to this, a study was conducted to see the potential of albumin being used as temporary medium to maintain the semen quality. If the postulation is right, the albumin solution media can be easily added on the semen sample and be stored in the freezer before sending it to designated remote farms for AI. Thus, eliminating the need for cryopreservation. We have also extended the study to see the ability of the medium to preserve and protect the cells while maintain sperm cell elasticity when preserved in albumin.

\section{Method}

\subsection{Sample Preparation}

This study was approved by our institutional review board (PP/FISIO/2011/FATIMAH/27JANUARY/357-JANUARY-2011-DECEMBER-2011). Fresh semen samples were collected from Bali cattles at Institut Bioteknologi Veterinar Kebangsaan, Jerantut, Pahang, Malaysia. The semen was collected through artificial vagina method by a certified personnel Bio-excel ${ }^{\circledR}$ Extender was added to the semen samples, and then it was packaged in 33 straws which were then cryopreserved. Each straw contained $0.25 \mathrm{ml}$ of semen with an average concentration of $40 \times 10^{6} \mathrm{sperms} / \mathrm{ml}$. All the straws were thawed in a water bath at $37^{\circ} \mathrm{C}$ for 30 seconds.

\subsection{Determination of Optimum Albumin-V Concentration on Bovine Spermatozoa Viability and Motility Using Light Microscope}

The semen was divided into control and test group. Control group is the samples without the addition of BSA, whereas the test groups were added with different concentrations of BSA which were prepared through dilution

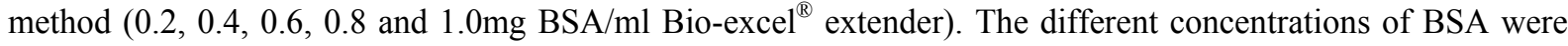
thawed in a water bath at $37^{\circ} \mathrm{C}$ for 30 seconds. After that, the BSA was added into the semen samples. Samples from each concentration were assessed on its motility, viability and membrane elasticity at 0 hours, 2 hours, 24 hours and 48 hours of incubation at $4^{\circ} \mathrm{C}$ as described by Thuan et al. (2005) (Van Thuan et al., 2005).

Makler chamber (Sefi Medical Instruments ltd., Haifa, Israel) was used in this experiment to determine the spermatozoa viability and motility. This procedure was repeated three times for each concentration at $0,2,24$ and 48 hours. The sperm motility then was categorized into four grades which are rapid progressive (A), slow or sluggish progressive (B), non-progressive (C) and immotile (D). The sperm motility percentage was defined as $(\mathrm{A}+\mathrm{B}) /(\mathrm{A}+\mathrm{B}+\mathrm{C}+\mathrm{D}) \%$ whereas the percentage of sperm viability was $(\mathrm{A}+\mathrm{B}+\mathrm{C}) /(\mathrm{A}+\mathrm{B}+\mathrm{C}+\mathrm{D}) \%$ according to $\mathrm{WHO}$ 
1992 recommendation. Graphs for sperm motility and viability rate of various concentrations of BSA against duration of time were also plotted for easy interpretation.

\subsection{Determination of Membrane Elasticity Using Atomic Force Microscope}

The elasticity properties of sperm were investigated by using Atomic Force Microscope (AFM), model Q250 (Ambios Co.) with Scan Atomic SPM Control Software. After considering the result in the sperm motility and viability, sperm incubated in $0.0,0.4$ and $1.0 \mathrm{mg} \mathrm{BSA} / \mathrm{ml}$ Bio-excel ${ }^{\circledR}$ extender at 48 hours were chosen for this part of the experiment. Control group was also used in this study and was represented by a fresh semen sample without the addition of any BSA. A total of $10 \mu \mathrm{l}$ of the sperm samples from each concentration were spread thinly on a clean slide and left to dry at room temperature. Once dried, the exposed AFM tip was lowered on the sperm surface. Force against sperm membrane was determined based on the amount of cantilever deflection. The indentations of the sperm cell membrane were performed at speed of $200 \mathrm{~nm} / \mathrm{s}$ and an indentation depth of $500 \mathrm{~nm}$. For each sample, three scanning cycles that contained 300 data points were done. The deflection signals produced by a laser light shilling on the cantilever deflection were detected by photodiode detector. This data was then transformed into curves of forces versus depth of AFM tip indentation. This graph was further modified to represent sperm elastic membrane through the use of a Hertz model.

\section{Results}

\subsection{Sperm Viability and Motility}

Bovine semen were incubated in various concentrations $\left(0.2,0.4,0.6,0.8\right.$ and $1.0 \mathrm{mg} \mathrm{BSA} / \mathrm{ml} \mathrm{Bio-excel}{ }^{\circledR}$ extender of bovine serum albumin in $4^{\circ} \mathrm{C}$. Our study showed that the viability (Figure 1) and motility (Figure 2) of sperm were different when examined at 2 hour, 24 hour, and 48 hour post incubation. Incubation of semen in control and in Albumin group has showed marked reduction in viability and motility over time.

At 2 hours of incubation, the control group $(0 \mathrm{mg} / \mathrm{ml}$ Albumin-V) showed highest percentage of viability and motility, followed by $0.2 \mathrm{mg} / \mathrm{ml}, 0.6 \mathrm{mg} / \mathrm{ml}, 0.4 \mathrm{mg} / \mathrm{ml}, 0.8 \mathrm{mg} / \mathrm{ml}$ and $1 \mathrm{mg} / \mathrm{ml}$ of Albumin-V. At 24 hours of incubation, sperm viability and motility were markedly reduced in all concentrations except sperm in $0.4 \mathrm{mg} / \mathrm{ml}$ BSA which had improved $1.8 \%$ and $1.07 \%$ respectively. At 48 hours of incubation, all sperm in various concentrations of Albumin-V showed decrease in viability and motility. However, generally both the viability and motility of sperm in $0.4 \mathrm{mg} / \mathrm{ml}$ Albumin was still the best compared to other test groups and even control.

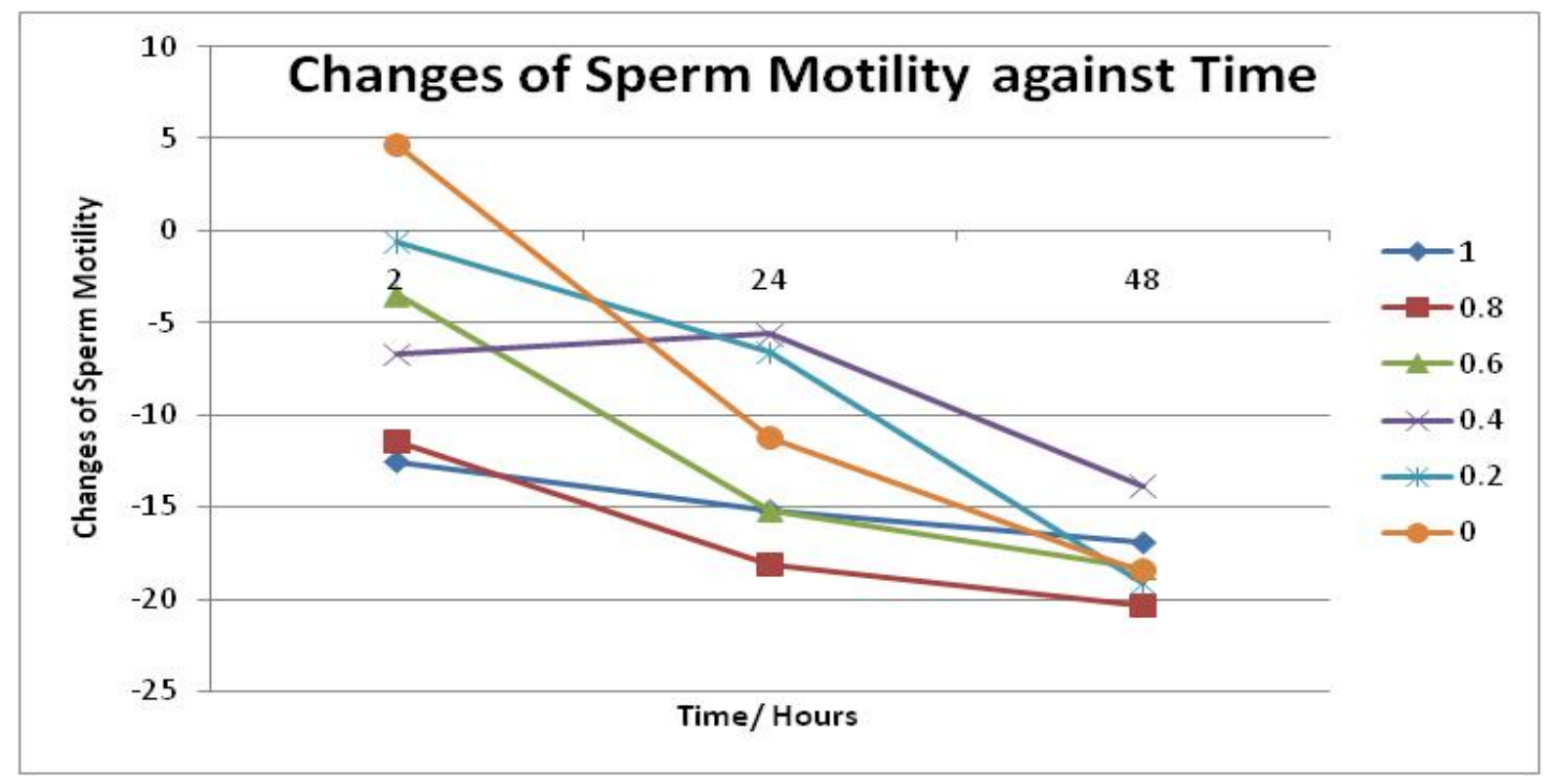

Figure 1. Changes of sperm viability in opposition to time (2. 24, and 48 hour). The different concentrations of Albumin-V $(0,0.2,0.4,0.6,0.8$, and $1.0 \mathrm{mg} / \mathrm{ml})$ were analyzed after incubation at $4^{\circ} \mathrm{C}$. Values are represented as Mean \pm SEM. Significant changes are indicated when $\mathrm{p}<0.05(\mathrm{n}=33)$ 


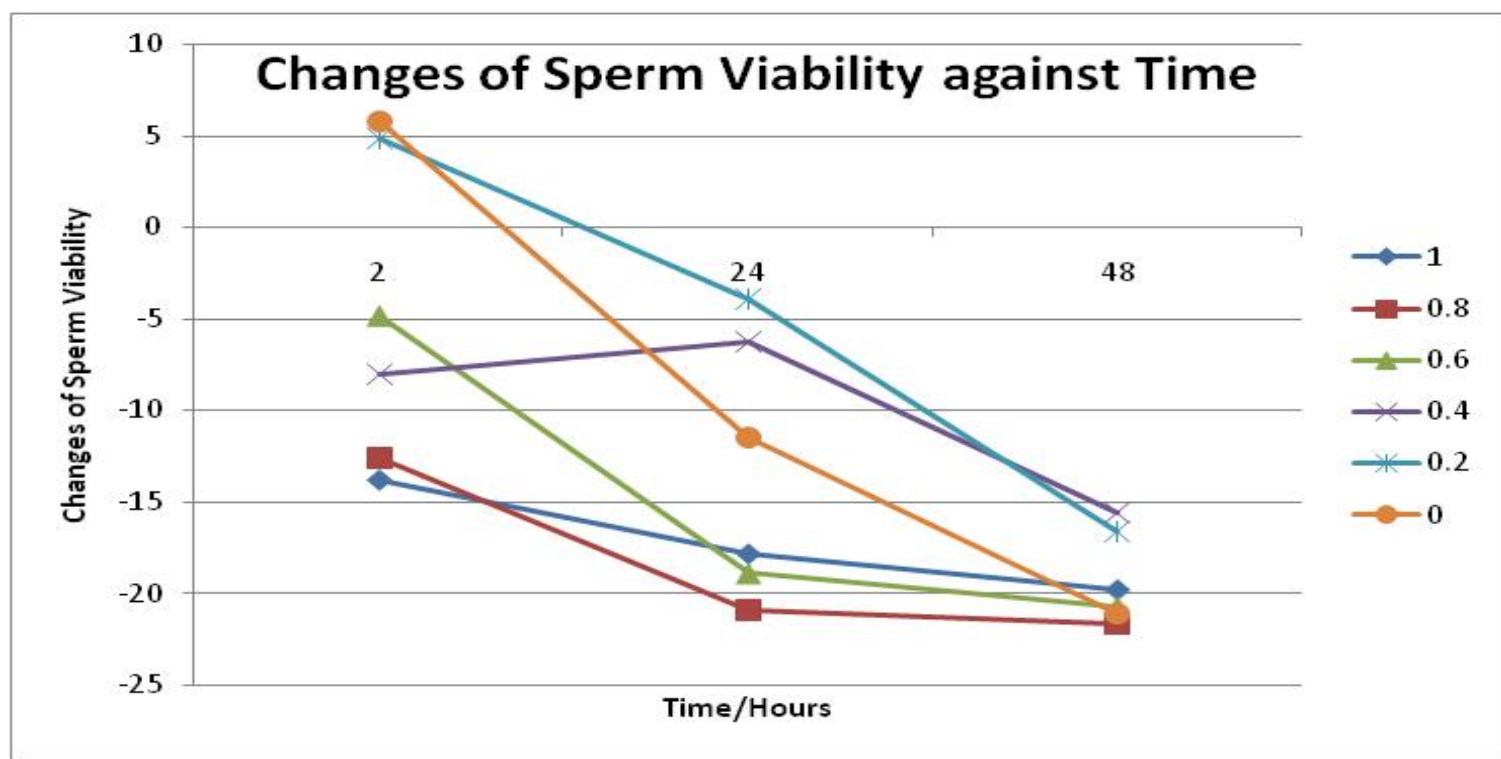

Figure 2. Changes of sperm motility in opposition to time (2. 24 and 48 hour). The different concentrations of Albumin-V $(0,0.2,0.4,0.6,0.8$, and $1.0 \mathrm{mg} / \mathrm{ml})$ were analyzed after incubation at $4^{\circ} \mathrm{C}$. Values are represented as Mean \pm SEM. Significant changes are indicated when $\mathrm{p}<0.05(\mathrm{n}=33)$

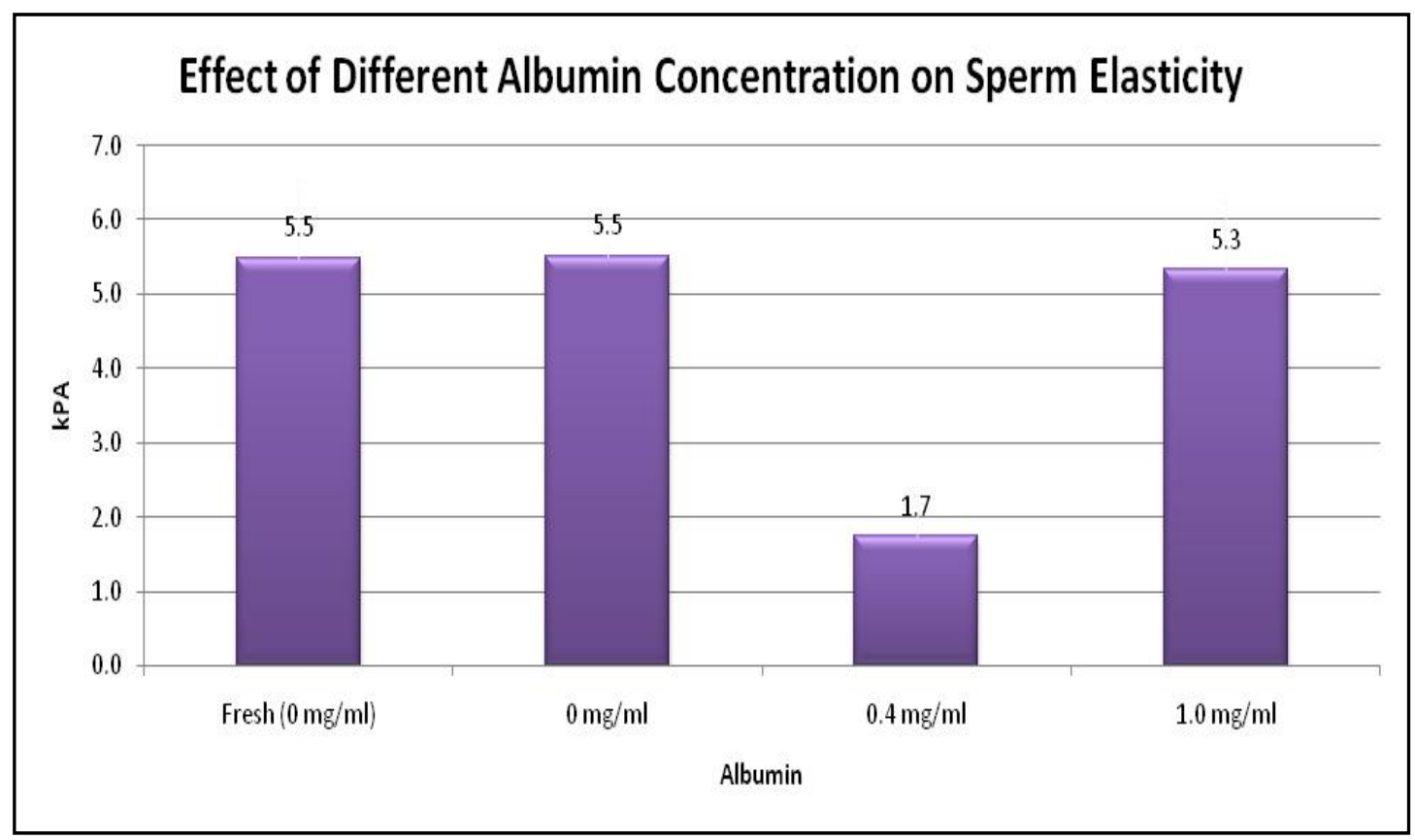

Figure 3. Sperm membrane elasticity (kPA) against fresh semen sample without BSA and different concentrations of BSA $(0,0.4$ and $1.0 \mathrm{mg} / \mathrm{ml})$ at 48 hours of incubation. AFM data was converted to $\mathrm{F}(\mathrm{h})$ through the formula

$$
F(h)=\frac{4 \sqrt{\mathrm{R}}}{3} \mathrm{E}^{*} \mathrm{~h}^{3 / 2}
$$

\subsection{Sperm Membrane Elasticity}

Figure 3 shows the result of the AFM data after being converted to $F(h)(k P A)$ through the formula mentioned above. The $F(h)$ represents the pressure needed to deform the sperm membrane indicate the elasticity of the membrane. The higher the $F(h)$, the more elastic the cell membrane. Result of the chart showed that the $F(h)$ for fresh semen sample, $0 \mathrm{mg} / \mathrm{ml}$ BSA, and $1.0 \mathrm{mg} / \mathrm{ml}$ Albumin-V were about the same (5.3-5.5 kPA). However, F(h) for $0.4 \mathrm{mg} / \mathrm{ml}$ sperm sample had showed marked reduction which indicates lower membrane elasticity. 


\section{Discussion}

As like any other living organism, spermatozoa needs nutrient to stay alive. It uses fructose and protein in seminal fluid to maintain its motility and viability (Ball, 2008). Studies have shown that $30 \%$ of proteins in semen are albumin. It has been postulated that albumin- $\mathrm{V}$ very likely is acting as an additional source of nutrient for spermatozoa metabolism (Owen \& Katz, 2005). Exposing fresh ejaculated semen to room temperature conditions would likely deplete the seminal fluid of any nutrients as they would likely have been consumed by the spermatozoa. This depletion would eventually lead to ATP deficits. Overall, this condition would disrupt the efficiency in sperm motility and affects its viability. This is clearly shown in our study from the medium that contain $0 \mathrm{mg} / \mathrm{ml}$ of albumin- $\mathrm{V}$. The viability and motility of the spermatozoa in this group were greatly reduced compared to test groups $(0.2,0.4,0.6,0.8$, and $1.0 \mathrm{mg} / \mathrm{ml}$ albumin-V). It is very likely that this event confirmed the albumin roles in ensuring the sperm motility and viability intact even after two days of storage at $4^{\circ} \mathrm{C}$.

We postulated that $0.4 \mathrm{mg} / \mathrm{ml}$ albumin- $\mathrm{V}$ is the optimum concentration to achieve a balanced isotonic intracellular environment for the sperm cells. A very high concentration of albumin would likely create a hypertonic environment while a lower concentration would possible result in a hypotonic environment for the sperm. If not optimized the osmotic stress would likely cause changes in cell volume due to the movement of water and solute across the sperm. Significant changes would likely have a direct impact on the cell membrane and ATP generation on the mitochondria and one third upper tail of the spermatozoa (Jones \& Bavister, 2000).

A continuous inappropriate osmotic condition would likely result in cell death. Previous studies had shown that cell death releases reactive oxygen species (ROS) into their micro-environment as a mechanism to digest the cells. The released ROS will accumulate and multiply in quantity due to the presence of large amount of unsaturated fatty acid (Lenzi et al., 1996; Lenzi et al., 2002). ROS from other sources including electron leakage from the spermatozoa mitochondria would also further worsen this problem. Continuous accumulation of ROS would lead to sharp increase in lipid peroxidation in the surrounding sperms. Since a spermatozoon has a high content of polyunsaturated fatty acids and low amount of anti-oxidant, the spermatozoa are more susceptible to lipid peroxidation process compared to other cells. When the production of ROS overwhelmed the limited antioxidant defence system, oxidative stress will occur in the cell. The peroxidation of lipid and dead spermatozoa will further exponentiate the problem since lipid peroxidation is a cascade reaction. The overall outcome would likely be what was seen in this study. The spermatozoa had lost their motility and become not viable.

Past studies have also indicated that the excessive endogenous oxidative stress could also induce significant DNA damage in the spermatozoa. Since the deoxyribonucleic acid bases and phosphodiester backbones are linked by double bonds, these molecules become very susceptible to peroxidation (Teebor et al., 1988). The loss of sperm's DNA integrity has been linked to a reduction of spermatozoa's viability (Uysal \& Bucak, 2007).

Lysozyme that had been released from the dead spermatozoa would also likely had a direct effect on plasma membrane destruction (Shimada et al., 2008). The proteolitic enzymes and the abundance of lactic acid would likely affect the sperm's membrane integrity significantly. With time, further accumulation of lactic acids from spermatozoa lyses and spermatozoa metabolism by products would slowly lower the surrounding seminal $\mathrm{pH}$. When the seminal $\mathrm{pH}$ becomes too acidic for the spermatozoa, the remaining spermatozoa will become less motile and viable (Jones \& Bavister, 2000). Based on this, it is quite likely that the addition of albumin into the seminal fluid could have played a significant and numerous roles in maintaining semen quality.

AFM studies of sperm elasticity revealed that various concentration of albumin had direct effect on spermatozoa membrane. Very likely the albumin had a protective effect on the spermatozoa, specifically against cell lyses. The mechanism of how this is achieved still eludes us but it is very likely due to the albumin's capability to eliminate crenation and reduce mechanical fragilities. The regulation of these two factors would likely maintain the elasticity of the spermatozoa thus stabilizing the cell shape (Jay, 1975; Williams \& Ford, 2001).

Despite the strong association between albumin concentration and spermatozoa membrane elasticity, definitive role of albumin on sperm elasticity is still unknown. A few AFM studies of type IV collagen, time dependant structural change, cell migration and mechanical properties of fibroblast had shown possible correlation between the time dependant changes of cell membrane and its elasticity. In this study, significant effect was seen four days after the incubation of type IV collagen in the fibroblast media. Thus, it is very likely that incubation time is a factor to consider when trying to obtain optimum spermatozoa cells elasticity (Hart et al., 2000).

We also would like to stress that, the optimum albumin concentration seen of this study is very specific to the breed of animal. Optimization will need to be done when applying this procedure on other species or even human due to the different composition of lipid, protein and carbohydrate present on spermatozoa membrane. Further studies will also need to be under taken to further understand how fast the spermatozoa membrane can change its elasticity, 
the best elasticity parameter of the sperm for fertilization and finally its impact on the successful rate of ART specifically AI.

\section{Conclusion}

Albumin- $\mathrm{V}$ at $0.4 \mathrm{mg} / \mathrm{ml}$ is a potential molecule for 24 and 48 hours $4{ }^{\circ} \mathrm{C}$ semen preservation for Bali cattle as they were able to retain mobility and viability. The group had also significant lower elasticity value compared to control and other test group.

\section{Acknowledgements}

This study had not been possible without the assistance of grant (10-05-ABI-AB040) from AgroBiotech Institute, Ministry of Science, Technology \& Innovation, Malaysia and technical assistance from Hi-Tech Instruments Sdn. Bhd.

\section{References}

Alvarez, J., \& Storey, B. (1995). Differential incorporation of fatty acids into and peroxidative loss of fatty acids from phospholipids of human spermatozoa. Molecular Reproduction \& Development, 42(3), 334-346. http://dx.doi.org/10.1002/mrd.1080420311

Ball, B. A. (2008). Oxidative stress, osmotic stress and apoptosis: impacts on sperm function and preservation in $\begin{array}{lllll}\text { the } & \text { horse. Animal }\end{array}$ http://dx.doi.org/10.1016/j.anireposci.2008.04.014

Blake, D., Svalander, P., Jin, M., Silversand, C., \& Hamberger, L. (2002). Protein supplementation of human IVF culture media. Journal of Assisted Reproduction and Genetics, 19(3), 137-143. http://dx.doi.org/10.1023/A:1014788821965

Bungum, M., Humaidan, P., Axmon, A., Spano, M., Bungum, L., Erenpreiss, J., \& Giwercman, A. (2007). Sperm DNA integrity assessment in prediction of assisted reproduction technology outcome. Human Reproduction, 22(1), 174-179. http://dx.doi.org/10.1093/humrep/del326

Cabrita, E., Anel, L., \& Herraez, M. P. (2001). Effect of external cryoprotectants as membrane stabilizers on cryopreserved rainbow trout sperm. Theriogenology, 56(4), 623-635. http://dx.doi.org/10.1016/S0093-691X(01)00594-5

Farstad, W., \& Berg, K. A. (1989). Factors influencing the success rate of artificial insemination with frozen semen in the dog. Journal of Reproduction and Fertility Supplement, 39, 289-292. http://dx.doi.org/PMid:2621730

Freeman, M. R., Archibong, A. E., Mrotek, J. J., Whitworth, C. M., Weitzman, G. A., \& Hill, G. A. (2001). Male partner screening before in vitro fertilization: preselecting patients who require intracytoplasmic sperm injection with the sperm penetration assay. Fertility and Sterility, 76(6), 1113-1118. http://dx.doi.org/10.1016/S0015-0282(01)02890-4

Ghuman, J., Zunszain, P. A., Petitpas, I., Bhattacharya, A. A., Otagiri, M., \& Curry, S. (2005). Structural basis of the drug-binding specificity of human serum albumin. Journal of Molecular Biology, 353(1), 38-52. http://dx.doi.org/10.1016/j.jmb.2005.07.075

Girasole, M., Pompeo, G., Cricenti, A., Longo, G., Boumis, G., Bellelli, A., \& Amiconi, S. (2010). The how, when, and why of the aging signals appearing on the human erythrocyte membrane: an atomic force microscopy study of surface roughness. Nanomed-Nanotechnol, 6(6), 760-768. http://dx.doi.org/10.1016/j.nano.2010.06.004

Hart, D. M., Norman, J., \& Callander, R. (2000). Gynaecology illustrated. Philadelphia: Churchill Livingstone.

Jay, A. W. (1975). Geometry of the human erythrocyte. I. Effect of albumin on cell geometry. Biophysical Journal, 15(3), 205-222. http://dx.doi.org/10.1016/S0006-3495

Jones, J. M., \& Bavister, B. D. (2000). Acidification of intracellular $\mathrm{pH}$ in bovine spermatozoa suppresses motility and extends viable life. Journal of Andrology, 21(5), 616.

Kothari, S., Thompson, A., Agarwal, A. \& du Plessis, S. S. (2010). Free radicals: Their beneficial and detrimental effects on sperm function. Indian Journal of Experimental Biology, 48(5),425-435. http://dx.doi.org/

Lenzi, A., Gandini, L., Lombardo, F., Picardo, M., Maresca, V., Panfili, E., ... Dondero, F. (2002). Polyunsaturated fatty acids of germ cell membranes, glutathione and blutathione-dependent 
enzyme-PHGPx: from basic to clinic. Contraception, 65(4), 301-304. http://dx.doi.org/10.1016/S0010-7824(02)00276-7

Lenzi, A., Picardo, M., Gandini, L., \& Dondero, F. (1996). Lipids of the sperm plasma membrane: from polyunsaturated fatty acids considered as markers of sperm function to possible scavenger therapy. Human Reproduction Update, 2(3), 246-256. http://dx.doi.org/10.1093/humupd/2.3.246

Orsini, F., Santacroce, M., Arosio, P., \& Sacchi, V. F. (2010). Observing Xenopus laevis oocyte plasma membrane by atomic force microscopy. Methods, 51(1), 106-113. http://dx.doi.org/10.1016/j.ymeth.2009.12.002

Owen, D. H., \& Katz, D. F. (2005). A review of the physical and chemical properties of human semen and the formulation of a semen simulant. Journal of Andrology, 26(4), 459. http://dx.doi.org/10.2164/jandrol.04104

Ruiz-Lopez, M. J., Evenson, D. P., Espeso, G., Gomendio, M., \& Roldan, E. R. S. (2010). High levels of DNA fragmentation in spermatozoa are associated with inbreeding and poor sperm quality in endangered ungulates. Biology of Reproduction, 83(3), 332-338. http://dx.doi.org/10.1095/biolreprod.110.084798

Shimada, I., Matsui, K., Brinkmann, B., Hohoff, C., Hiraga, K., Tabuchi, Y., ... Takasawa, K. (2008). Novel transcript profiling of diffuse alveolar damage induced by hyperoxia exposure in mice: normalization by glyceraldehyde 3-phosphate dehydrogenase. International Journal of Legal Medicine, 122(5), 373-383. http://dx.doi.org/10.1007/s00414-008-0226-6

Teebor, G. W., Boorstein, R. J., \& Cadet, J. (1988). The repairability of oxidative free radical mediated damage to DNA: a review. International Journal of Radiation Biology, 54(2), 131-150. http://dx.doi.org/10.1080/09553008814551591

Uysal, O., \& Bucak, M. N. (2007). Effects of oxidized glutathione, bovine serum albumin, cysteine and lycopene on the quality of frozen-thawed ram semen. Acta Veterinaria Brno, 76(3), 383-390. http://dx.doi.org/10.2754/avb200776030383

Van Thuan, N., Wakayama, S., Kishigami, S., \& Wakayama, T. (2005). New preservation method for mouse spermatozoa without freezing. Biology of Reproduction, 72(2), 444-450. http://dx.doi.org/10.1095/biolreprod.104.034678

Williams, A. C., \& Ford, W. C. L. (2001). The role of glucose in supporting motility and capacitation in human spermatozoa. Journal of Andrology, 22(4), 680-695. http://dx.doi.org/PMid:11451366 